\title{
AxiaLIF system: minimally invasive device for presacral lumbar interbody spinal fusion
}

This article was published in the following Dove Press journal:

Medical Devices: Evidence and Research

I2 August 201 I

Number of times this article has been viewed

\section{Steven M Rapp' \\ Larry E Miller ${ }^{2,3}$ \\ Jon E Block ${ }^{3}$}

'Michigan Spine Institute, Waterford, MI, USA; ${ }^{2}$ Miller Scientific Consulting Inc, Biltmore Lake, NC, USA; ${ }^{3}$ Jon E. Block, Ph.D., Inc., San Francisco, CA, USA
Correspondence: Jon E Block 2210 Jackson Street, Suite 40I, San Francisco, CA 94II5, USA

$\mathrm{Tel}+\mathrm{I} 4157757947$

Fax + I 4I59280765

Email jonblock@jonblockphd.com

\begin{abstract}
Lumbar fusion is commonly performed to alleviate chronic low back and leg pain secondary to disc degeneration, spondylolisthesis with or without concomitant lumbar spinal stenosis, or chronic lumbar instability. However, the risk of iatrogenic injury during traditional anterior, posterior, and transforaminal open fusion surgery is significant. The axial lumbar interbody fusion (AxiaLIF) system is a minimally invasive fusion device that accesses the lumbar (L4-S1) intervertebral disc spaces via a reproducible presacral approach that avoids critical neurovascular and musculoligamentous structures. Since the AxiaLIF system received marketing clearance from the US Food and Drug Administration in 2004, clinical studies of this device have reported high fusion rates without implant subsidence, significant improvements in pain and function, and low complication rates. This paper describes the design and approach of this lumbar fusion system, details the indications for use, and summarizes the clinical experience with the AxiaLIF system to date.
\end{abstract}

Keywords: AxiaLIF, fusion, lumbar, minimally invasive, presacral

\section{Introduction}

Disabling low back pain is a common medical complaint, with a lifetime prevalence of $60 \%-90 \%$ for a single episode ${ }^{1,2}$ and $14 \%$ for pain of at least two weeks' duration. ${ }^{3}$ Low back pain is responsible for 62 million physician visits per year in the $\mathrm{US}^{4}$ and the prevalence of this condition is anticipated to increase over time. ${ }^{5}$ Chronic low back pain is associated with advanced age, depression, obesity, and heavy physical exertion, ${ }^{6}$ and is responsible for permanent disability in $1 \%$ of adults in the US. ${ }^{7}$ Identification of the etiology of low back pain is complicated, given the weak association between patient symptoms and radiographic imaging results. ${ }^{8}$ Indeed, a definitive diagnosis is established in only $20 \%$ of cases. $^{9}$

Most cases of low back pain will eventually resolve with nonsurgical management. However, conservative treatments for refractory chronic low back pain have limited effectiveness. ${ }^{10,11}$ When conservative care options have been exhausted without success, definitive operative correction is often necessary. Lumbar fusion is a common surgery to alleviate low back pain, often with concomitant radicular symptoms, by decompressing offending neurological elements and reducing instability, with over 122,000 lumbar fusion surgeries performed each year in the US alone. ${ }^{12}$ A variety of open lumbar fusion approaches are available to the spine surgeon, including anterior lumbar interbody fusion, posterior lumbar interbody fusion, transforaminal lumbar interbody fusion, and circumferential or 360 degree (anterior lumbar interbody fusion 
with posterior lumbar interbody fusion or transforaminal lumbar interbody fusion). However, regardless of the surgical approach, each of these procedures is associated with inherent procedural risks.

An anterior lumbar interbody fusion requires retraction of and navigation around major organs and blood vessels, which places these structures at risk for iatrogenic injury. ${ }^{13-15}$ The posterior lumbar interbody fusion procedure results in significant musculoligamentous injury, as well as nerve root injury and spinal fluid leakage. ${ }^{16-19}$ Transforaminal lumbar interbody fusion utilizes a unilateral exposure with a theoretically lower risk of iatrogenic injury, although safety concerns with this technique persist. ${ }^{20,21}$ Because of the significant morbidity associated with these open procedures, a trend has recently developed towards utilizing minimally invasive approaches for lumbar fusion. ${ }^{22,23}$ Despite the smaller incision and minimal disruption of nearby anatomical structures, these techniques still utilize the same anatomical approach as traditional open procedures and, therefore, vital organs and major nerves and arteries remain at risk for injury.

The axial lumbar interbody fusion (AxiaLIF) system (TranS1 Inc, Wilmington, NC) is a minimally invasive fusion device that utilizes the same surgical principles as other open fusion approaches, with the primary difference related to access location. This technique accesses the lumbar vertebrae via a reproducible anatomical pathway, ie, a presacral approach through a small paracoccygeal incision, which is perpendicular to the plane utilized in other surgical techniques. Unlike other approaches, the AxiaLIF procedure avoids critical neurovascular and musculoligamentous structures and may offer distinct safety advantages. ${ }^{24}$ Furthermore, the minimally invasive, atraumatic nature of the AxiaLIF procedure greatly minimizes surgical scarring, which may lower the risk of failed back syndrome, ${ }^{25,26}$ and is ideal in case of future revision or adjacent level surgery. The purpose of this paper is to describe this lumbar fusion device and to detail the indications for use and clinical experience to date with the AxiaLIF system.

\section{Device description, procedural technique, and indications for use}

The AxiaLIF system received marketing clearance for single-level lumbar fusion (L5/S1) from the US Food and Drug Administration in 2004. ${ }^{27}$ The AxiaLIF 360 (AxiaLIF system combined with facet screws), approved by the Food and Drug Administration in $2005,{ }^{28}$ affords the option of a circumferential lumbar fusion through a minimally invasive approach. The AxiaLIF 2-level system was cleared by the Food and Drug Administration in 2008 for two-level fusion (L4-S1) procedures. ${ }^{29}$ To date, over 10,000 minimally invasive fusion procedures have been performed using these devices.

\section{Preoperative care}

The preoperative evaluation for the AxiaLIF procedure includes routine imaging studies to determine the indication for lumbar fusion. Magnetic resonance imaging of the sacrum and coccyx is performed to ensure there are no anatomic barriers to a safe procedure (eg, bowel adhesions, tumor, or vascular anomaly) and the sagittal sacral curve is evaluated to confirm feasibility of the approach (Figure 1). In order to lower the risk of iatrogenic bowel perforation, preoperative patient preparation includes mechanical bowel cleansing and broad-spectrum intravenous antibiotic administration.

\section{Procedural technique}

Under general anesthesia, the patient is positioned prone on a radiolucent operative table. A catheter is optionally inserted into the rectum so that air or contrast can be injected during the procedure to enhance rectal visualization. The single-level AxiaLIF fusion procedure, which is performed entirely under fluoroscopy with no direct visualization of the operative field, begins by creating a $2 \mathrm{~cm}$ longitudinal incision at the level of the paracoccygeal notch. A blunt cannulated dissector is advanced through the avascular presacral space and is docked onto the sacrum in the desired location for screw entry (Figure 2). A stout guide pin is then introduced through the dissector into the sacrum and advanced into the disc space. A series of dilators are advanced over the guide pin and a working cannula is anchored to the sacrum. A cannulated drill is then passed over the guide pin and a transsacral portal is created into the L5/S1 disc space. Nitinol cutters are inserted sequentially into the disc space to debulk the nucleus pulposus and decorticate the superior and inferior endplates, which provides a cancellous osteogenic bed to promote bony fusion. The disc space is prepared for bone grafting by removing diseased disc material with tissue extractors. Autologous bone and bone graft extenders and/or bone morphogenic protein are then inserted into the disc space.

Following bone graft placement, the guide pin can be replaced and advanced into the inferior endplate of L5. A twist drill is used to create a channel through the vertebral body of L5 but without violating the superior endplate of L5 or the $\mathrm{L} 4 / 5$ disc space. The guide pin is then advanced to 

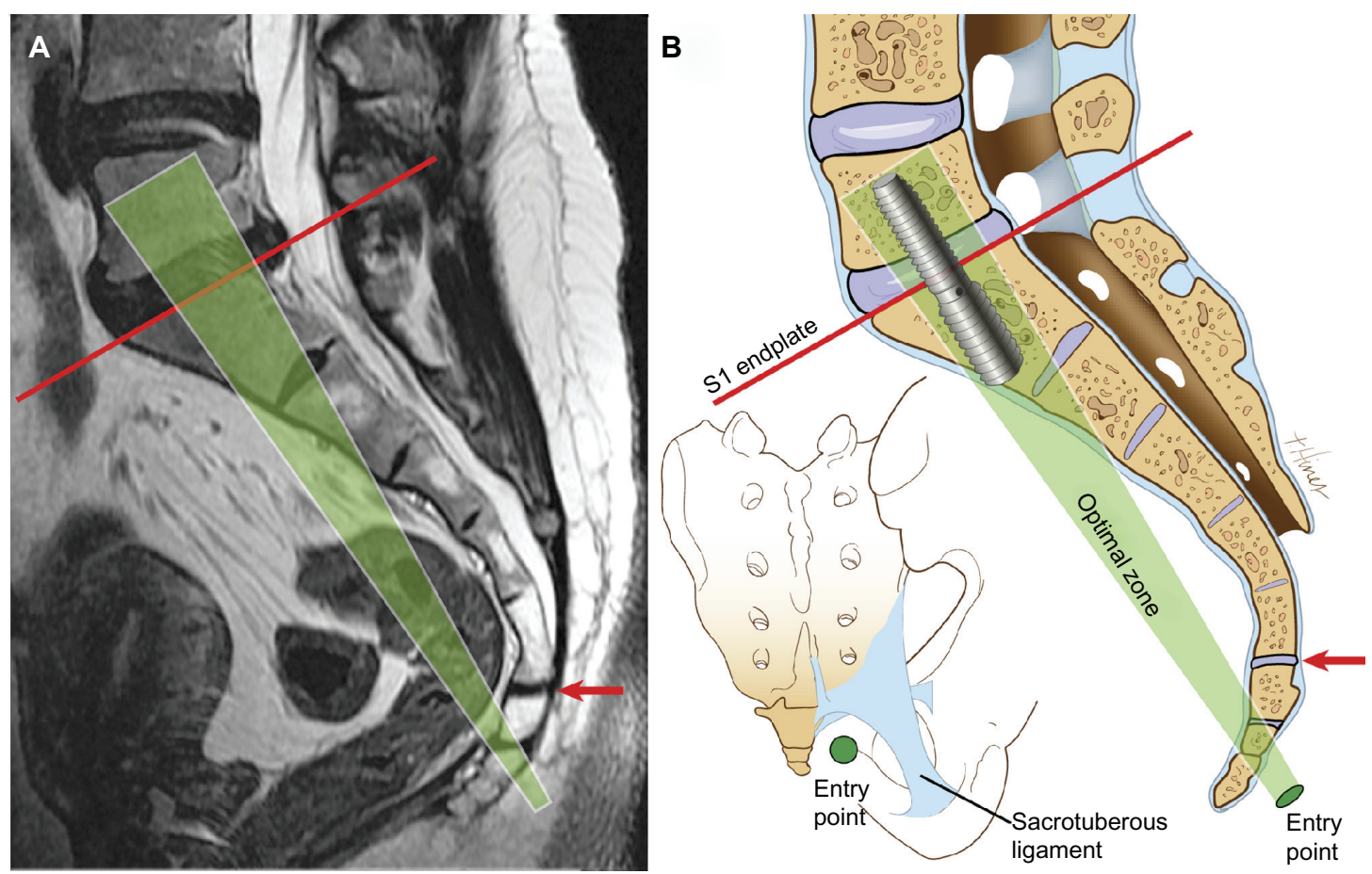

Figure I Preoperative evaluation of the sacrum and coccyx for the presacral AxiaLIF procedure. A line is drawn on the mid sagittal magnetic resonance scan from the probe entry point below the sacrococcygeal joint (red arrow) to the midpoint of the SI endplate (red line) in order to evaluate the feasibility of the approach. The optimal trajectory (green shaded area) of the implant is perpendicular to the superior endplate of SI, demonstrated in (A) magnetic resonance scan and (B) illustration. Illustration of the posterior sacrum shows the probe entry point lateral to the coccyx and inferior to the attachments of the sacrospinous and sacrotuberous ligaments.

Reprinted from Bohinski RJ, Jain VV, Tobler WD. Presacral retroperitoneal approach to axial lumbar interbody fusion: A new, minimally invasive technique at L5-SI: Clinical outcomes, complications, and fusion rates in 50 patients at I-year follow-up. SAS J. 2010;4:54-62. Copyright (C) 20I0, with permission from Elsevier. ${ }^{32}$

Abbreviation: AxiaLIF, axial lumbar interbody fusion.

the proximal end of the L5 drill hole. The cannula that was docked in the sacrum is removed, and a larger cannula that can accommodate the axial rod is inserted and advanced over the guidewire until flush against the anterior sacral face, where it is secured to the sacrum with a K-wire. A variety of lengths are available in the rod-shaped titanium alloy AxiaLIF system. Additionally, by using a different thread pitch in the S1 section of the axial rod as compared with the L5 section, distraction of the disc space can be achieved. There are three choices of differential pitches, depending on how much disc space distraction is desired. The AxiaLIF system is then placed over the guide pin and advanced through the sacrum into L5, to the proximal extent of the drilling. Additional graft material may be inserted via syringe into the disc space through the central rod portals. Minimally invasive placement of pedicle or facet screws is used to provide supplemental posterior fixation. The cannula is then removed and the wound is sutured in routine fashion. Lastly, air or contrast may be injected into the rectal catheter to inspect for iatrogenic bowel injury. The implanted AxiaLIF device is shown in Figures 3 and 4.

The two-level system follows similar procedural steps as the single-level procedure with minor modifications.
The two-level system requires additional steps after grafting of the L5/S1 disc space to allow for access, decortication, and grafting of the L4/5 disc space. Also, the two-level rod is a modular two-piece rod that can be built according to desired lengths for each segment.

\section{Postoperative care}

Patient monitoring following an AxiaLIF procedure varies according to overall patient health and the standard practice of the surgeon. In general, patients are discharged from the hospital within two days of the procedure and return for follow-up visits at 2-4 weeks, 3-6 months, and one year. Patient restrictions in the postoperative period are similar to those of traditional lumbar fusion procedures, including avoidance of bending and twisting at the waist, heavy lifting, and strenuous physical activity.

\section{Indications for use}

The AxiaLIF system is intended for fusion of the L5/S1 spinal segment (two-level system for L4-S1 fusion) in conjunction with legally marketed facet or pedicle screw systems. Indications for use include patients requiring fusion to treat pseudoarthrosis, spinal stenosis, spondylolisthesis (one-level, 

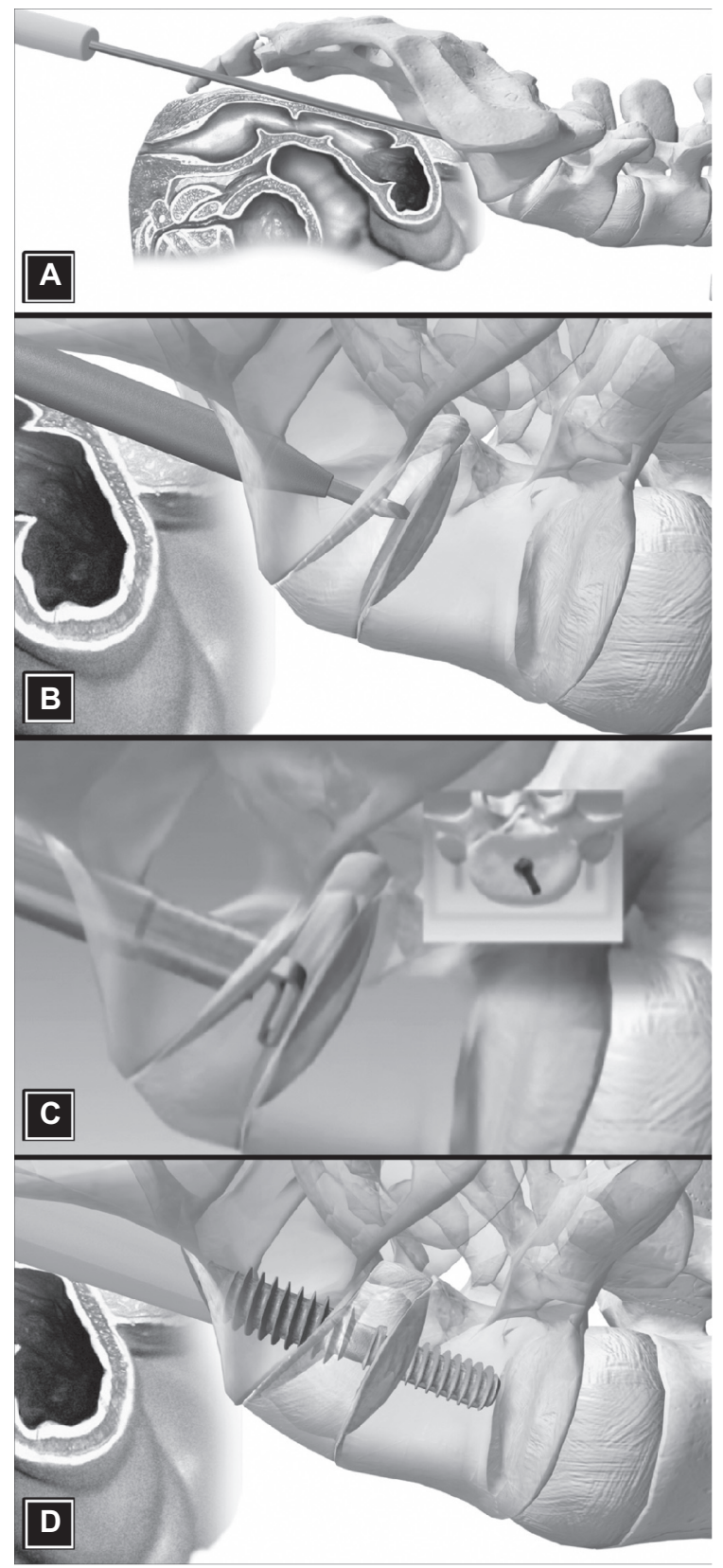

Figure 2 Presacral access with the AxiaLIF system. An incision is made lateral to the tip of the coccyx. The dissecting tool is slightly rotated to align with the presacral corridor and then advanced to the docking point on the sacrum. (A) Guide pin in presacral space docked on the sacrum. (B) Dilator and guide pin advanced into the L5/SI interspace. (C) Nitinol cutters debulking disc material and preparing the endplates for fusion. Note that arc of the cutter can be rotated 360 degrees (inset). (D) Finally, the AxiaLIF rod is implanted, distracting the interspace and providing L5/SI stabilization with placement of bone graft.

Abbreviation: AxiaLIF, axial lumbar interbody fusion.

grade 1 or 2; two-level, grade 1), or clinical or radiographic diagnosis of degenerative disc disease. AxiaLIF is also indicated for treatment of unsuccessful previous fusion. The AxiaLIF system may also be utilized for minimally invasive access to the anterior portion of the lower spine for assisting in the treatment of lumbar disc degeneration,

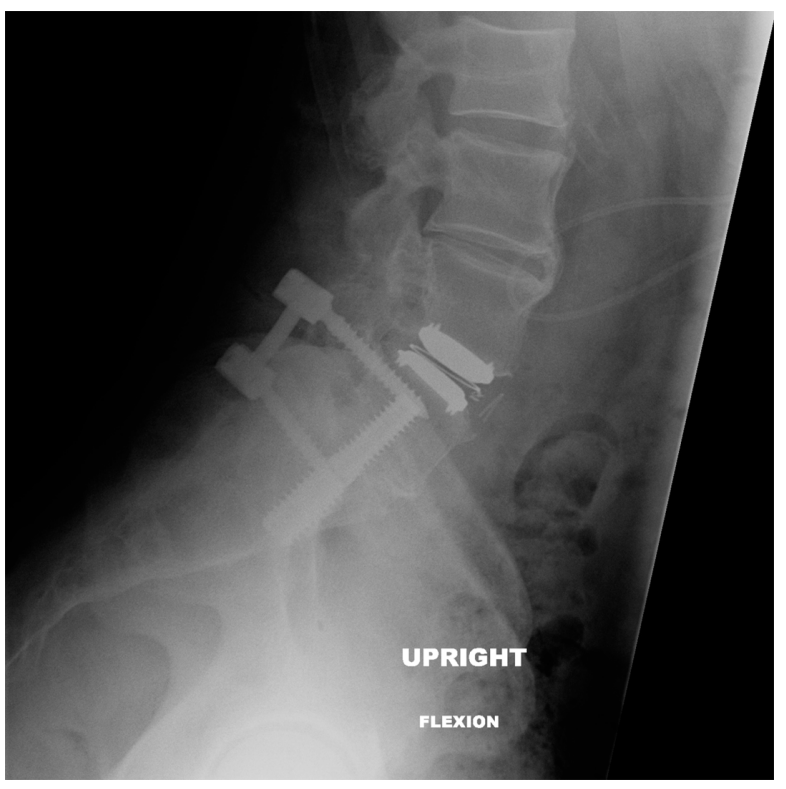

Figure 3 The implanted AxiaLIF device. Lateral radiographic view of L5/SI fusion with the patient in flexion. Note the AxiaLIF fusion construct directly caudal to an artificial disc replacement implanted at L4/L5.

Abbreviation: AxiaLIF, axial lumbar interbody fusion.

performing lumbar discectomy, or for assistance in the performance of L5/S1 interbody fusion (two-level system for L4-S1 fusion).

\section{Warnings and contraindications}

The AxiaLIF system is not intended to treat severe scoliosis, severe spondylolisthesis (grade 3 or 4), tumor, or trauma.

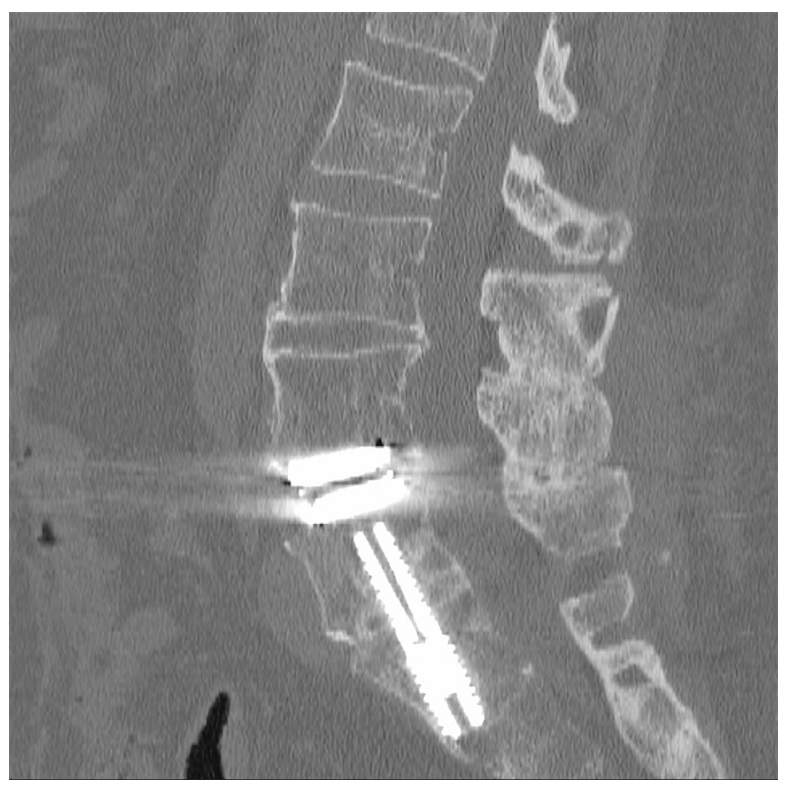

Figure 4 Computed tomography evaluation of the AxiaLIF device. Corresponding mid sagittal thin cut computed tomography image in the same patient demonstrating excellent device placement at L5/SI.

Abbreviation: AxiaLIF, axial lumbar interbody fusion. 
Contraindications for use include coagulopathy, bowel disease, pregnancy, and sacral agenesis. Usage of the AxiaLIF system is limited to anterior fusion of the lumbar spine at L5/ S1 (two-level system for L4-S1) in conjunction with legally marketed posterior fixation systems. The AxiaLIF system should not be used with facet screws when spinal stenosis correction requires removal of significant portions of the lamina or any portion of the facets. The two-level system is additionally contraindicated for patients with vertebral compression fractures or any other condition where the mechanical integrity of the vertebral body is compromised.

\section{Clinical outcomes}

The initial clinical experience with axial interbody lumbar fusion suggests that it provides discernible improvements in patient-reported outcomes with high fusion success and low complication rates. ${ }^{30,31}$ Aryan et $\mathrm{al}^{30}$ followed 35 patients with degenerative disc disease as the primary diagnosis for 18 months after axial interbody lumbar fusion. At the last follow-up visit, 91\% (32 of 35) of patients had radiographic evidence of stable L5/S1 interbody implant placement and fusion. Similarly, Stippler et $\mathrm{al}^{31}$ reported that $92 \%$ (33 of 36) of patients undergoing axial interbody lumbar fusion experienced a significant improvement or complete resolution of low back pain at final follow-up, with 31 cases $(86 \%)$ demonstrating a solid fusion radiographically.

The largest series of patients with one-year follow-up data was published by Bohinski et $\mathrm{al}^{32}$ who followed 50 patients for a minimum of one year after the AxiaLIF procedure. At one year post-treatment, subject-reported pain decreased by $49 \%$ from a visual analog scale preoperative score of
$77 \mathrm{~mm}$ to $39 \mathrm{~mm}$. Back function improved by $50 \%$ from $56 \%$ to $28 \%$ on the Oswestry Disability Index over the same follow-up period. Fusion success at L5/S1 was 100\% using plain radiographs and $88 \%$ using computed tomography. Finally, the complication rate was $2 \%$, which compares favorably with other open approaches.

As a whole, the initial experience with the AxiaLIF device demonstrates high (85\%-93\%) fusion rates, significant improvements in pain and function, low complication rates $(0 \%-3 \%)$, minimal procedural blood loss $(30-88 \mathrm{cc})$, and a short hospitalization stay (1.0-2.6 days). ${ }^{30,31,33-36}$

According to data collected by TranS1 Inc, through ongoing voluntary postmarketing surveillance, complications were reported in $120(1.3 \%)$ of 9152 patients treated with the AxiaLIF system $^{37}$ (Table 1). The median time from the index operative procedure to the report of the complication was five days (mean 33, range 0-511 days) with 90\% occurring within 90 days. The overall complication rate was similar $(P=0.43)$ between single-level $(\mathrm{n}=102,1.3 \%)$ and twolevel $(\mathrm{n}=18,1.6 \%)$ fusion procedures, with no significant differences noted for any single complication. The most commonly reported complication was bowel injury $(n=59$, $0.6 \%$ ). Median time from surgery to detection of bowel injury was three days (mean 4, range 0-48 days) with 77\% of these patients requiring colostomy. All complications were successfully treated and resolved with no further sequelae.

\section{Discussion}

Minimally invasive axial interbody lumbar fusion via a presacral approach is a technically feasible procedure that affords similar clinical outcomes versus standard

Table I Perioperative complications with lumbar fusion using the AxiaLIF ${ }^{\circledR}$ system

\begin{tabular}{|c|c|c|c|c|}
\hline Complication & $\begin{array}{l}\text { All patients } \\
n=9,152\end{array}$ & $\begin{array}{l}\text { Single-level } \\
n=8,034\end{array}$ & $\begin{array}{l}\text { Two-level } \\
n=1,118\end{array}$ & $P$ value* \\
\hline Number of complications & 123 & 103 & 20 & \\
\hline Patients with $\geq$ one complication & $120(1.3)$ & $102(1.3)$ & $18(1.6)$ & 0.43 \\
\hline Bowel injury & $59(0.6)$ & $50(0.6)$ & $9(0.8)$ & 0.61 \\
\hline Hypotension & $20(0.2)$ & $18(0.2)$ & $2(0.2)$ & 0.96 \\
\hline Presacral hematoma & $9(0.1)$ & $7(0.1)$ & $2(0.2)$ & 0.68 \\
\hline Sacral fracture & $7(0.1)$ & $5(0.1)$ & $2(0.2)$ & 0.46 \\
\hline Vascular injury & $6(0.1)$ & $5(0.1)$ & $I(0.1)$ & 0.77 \\
\hline Systemic infection & $6(0.1)$ & $6(0.1)$ & 0 & 0.77 \\
\hline Migration & $5(0.1)$ & $4(0.1)$ & $\mathrm{I}(0.1)$ & 0.60 \\
\hline Subsidence & $4(<0.1)$ & $3(<0.1)$ & $I(0.1)$ & 0.99 \\
\hline Nerve injury & $3(<0.1)$ & $2(<0.1)$ & $I(0.1)$ & 0.81 \\
\hline Superficial wound infection & $3(<0.1)$ & $2(<0.1)$ & $\mathrm{I}(0.1)$ & 0.81 \\
\hline Ureter injury & $\mathrm{I}(<0 . \mathrm{I})$ & $\mathrm{I}(<0 . \mathrm{I})$ & 0 & 0.25 \\
\hline
\end{tabular}

Notes: Data reported to TranSI Inc, as part of ongoing voluntary postmarketing surveillance. *Single-level versus two-level. Percentage values are expressed within parentheses.

Abbreviation: AxiaLIF, axial lumbar interbody fusion. 
fusion approaches, but with a lower risk of perioperative complications. This technique, utilizing an avascular axial corridor to attain vertebral access, offers the advantage of sparing the posterior musculature, ligaments, and neural elements that are encountered during posterior approaches, as well as avoiding dissection and retraction of major vessels and the intra-abdominal viscera as with anterior approaches.

The complication rates $(0 \%-3 \%)$ observed with the AxiaLIF system compare favorably with the typical $10 \%-15 \%$ complication rate reported in six trials regulated by the Food and Drug Administration using open lumbar fusion for degenerative disc disease as a control. ${ }^{38-43}$ Furthermore, serious adverse events, such as nerve injury $(0 \%-2.0 \%)$, vascular injury $(1.5 \%-8.8 \%)$, and infection $(0 \%-1.3 \%)$, were commonly reported in these trials, whereas these complications are extremely rare with the AxiaLIF procedure.

Minimally invasive axial interbody lumbar fusion using a presacral approach results in acceptable safety and effectiveness. However, there are some limitations with the AxiaLIF procedure that must be considered. The procedure requires spinal surgeons to become intimately familiar with presacral anatomy because the entire procedure is visualized under fluoroscopy with no direct observation of the disc space. ${ }^{44}$ Iatrogenic bowel perforation is a rare, but possible, complication of the AxiaLIF procedure that can be largely avoided with the appropriate preoperative patient preparation and meticulous surgical technique. Preoperative imaging should be thoroughly evaluated, with emphasis on perirectal fat pad thickness, identification of the rectum/sacrum interface, aberrant vasculature, and anticipated trajectory. Preoperative patient preparation includes mechanical bowel cleansing to enhance rectal pliability during blunt dissection and to lower contamination risk in the event of bowel injury. Administration of broad-spectrum intravenous antibiotics before the procedure further lowers the contamination risk. During the procedure, Foley catheter placement in the rectum helps to define the interface of the rectal wall and sacrum under fluoroscopy. A meticulous initial incision followed by gentle blunt dissection with the finger allows for safe entry into the presacral area. Postoperatively, endoscopic evaluation of the rectum and sigmoid colon helps to rule out bowel injury. Special attention to potential bowel complications should be given to women because the presacral width is narrower compared with males. ${ }^{45}$

Identification of low rectal injuries requires hospital admission, intravenous antibiotics, and bowel rest (no food or drink) with serial imaging. High rectal injuries are potentially more serious and treatment decisions are based primarily on the presence or absence of systemic complications. Patients with no systemic complications may be managed with observation, bowel rest, and intravenous antibiotics although surgical repair may be indicated in some cases. Patients with high rectal injury that present with fever and sepsis may additionally require pelvic drainage and a diverting stoma to achieve symptom resolution.

\section{Conclusion}

Minimally invasive axial interbody lumbar fusion via a presacral approach is a technically feasible procedure that is associated with high fusion rates, significant improvements in pain and function, and low complication rates.

\section{Acknowledgment}

We thank Mr Randy Asher for graphical assistance.

\section{Disclosure}

LEM and JEB received financial support from TranS1 Inc for assistance with manuscript development.

Otherwise the authors report no conflicts of interest in this work.

\section{References}

1. Rubin DI. Epidemiology and risk factors for spine pain. Neurol Clin. 2007;25:353-371.

2. Andersson GB. Epidemiology of low back pain. Acta Orthop Scand Suppl. 1998;281:28-31.

3. Deyo RA, Tsui-Wu YJ. Descriptive epidemiology of low-back pain and its related medical care in the United States. Spine (Phila Pa 1976). 1987;12:264-268.

4. Licciardone JC. The epidemiology and medical management of low back pain during ambulatory medical care visits in the United States. Osteopath Med Prim Care. 2008;2:11.

5. Freburger JK, Holmes GM, Agans RP, et al. The rising prevalence of chronic low back pain. Arch Intern Med. 2009;169:251-258.

6. Valat JP, Goupille P, Vedere V. Low back pain: Risk factors for chronicity. Rev Rhum Engl Ed. 1997;64:189-194.

7. Frymoyer JW, Cats-Baril WL. An overview of the incidences and costs of low back pain. Orthop Clin North Am. 1991;22:263-271.

8. Wand BM, O'Connell NE. Chronic non-specific low back pain sub-groups or a single mechanism? BMC Musculoskelet Disord. 2008;9:11.

9. Albert HB, Kjaer P, Jensen TS, Sorensen JS, Bendix T, Manniche C. Modic changes, possible causes and relation to low back pain. Med Hypotheses. 2008;70:361-368.

10. Frank AO, De Souza LH. Conservative management of low back pain. Int J Clin Pract. 2001;55:21-31.

11. Lee D. Low back pain intervention: Conservative or surgical? J Surg Orthop Adv. 2003;12:200-202.

12. Deyo RA, Gray DT, Kreuter W, Mirza S, Martin BI. United States trends in lumbar fusion surgery for degenerative conditions. Spine (Phila Pa 1976). 2005;30:1441-1445.

13. Baker JK, Reardon PR, Reardon MJ, Heggeness MH. Vascular injury in anterior lumbar surgery. Spine (Phila Pa 1976). 1993;18:2227-2230. 
14. Rajaraman V, Vingan R, Roth P, Heary RF, Conklin L, Jacobs GB. Visceral and vascular complications resulting from anterior lumbar interbody fusion. J Neurosurg. 1999;91(1 Suppl):60-64.

15. Garg J, Woo K, Hirsch J, Bruffey JD, Dilley RB. Vascular complications of exposure for anterior lumbar interbody fusion. JVasc Surg. 2010;51: 946-950.

16. Moskowitz A. Transforaminal lumbar interbody fusion. Orthop Clin North Am. 2002;33:359-366.

17. Cho KJ, Suk SI, Park SR, et al. Complications in posterior fusion and instrumentation for degenerative lumbar scoliosis. Spine (Phila Pa 1976). 2007;32:2232-2237.

18. Hosono N, Namekata M, Makino T, et al. Perioperative complications of primary posterior lumbar interbody fusion for nonisthmic spondylolisthesis: Analysis of risk factors. J Neurosurg Spine. 2008;9:403-407.

19. Scaduto AA, Gamradt SC, Yu WD, Huang J, Delamarter RB, Wang JC. Perioperative complications of threaded cylindrical lumbar interbody fusion devices: Anterior versus posterior approach. J Spinal Disord Tech. 2003;16:502-507.

20. Rihn JA, Patel R, Makda J, et al. Complications associated with single-level transforaminal lumbar interbody fusion. Spine J. 2009;9: 623-629.

21. Peng CW, Yue WM, Poh SY, Yeo W, Tan SB. Clinical and radiological outcomes of minimally invasive versus open transforaminal lumbar interbody fusion. Spine (Phila Pa 1976). 2009;34:1385-1389.

22. Mayer HM. A new microsurgical technique for minimally invasive anterior lumbar interbody fusion. Spine (Phila Pa 1976). 1997;22: 691-699.

23. Regan JJ, Yuan H, McAfee PC. Laparoscopic fusion of the lumbar spine: Minimally invasive spine surgery. A prospective multicenter study evaluating open and laparoscopic lumbar fusion. Spine (Phila Pa 1976). 1999;24:402-411.

24. Yuan PS, Day TF, Albert TJ, et al. Anatomy of the percutaneous presacral space for a novel fusion technique. J Spinal Disord Tech 2006;19:237-241.

25. Rabb CH. Failed back syndrome and epidural fibrosis. Spine J. 2010;10: 454-455.

26. Robertson JT. Role of peridural fibrosis in the failed back: A review. Eur Spine J. 1996;5 Suppl 1:S2-S6.

27. Food and Drug Administration. Summary: TranS1 axial fixation system. 2004. Available from: http://www.accessdata.fda.gov/cdrh_docs/pdf4/ K040426.pdf. Accessed July 21, 2011.

28. Food and Drug Administration. Summary: TranS1 AxiaLIF system. 2005. Available from: http://www.accessdata.fda.gov/cdrh_docs/pdf5/ K050965.pdf. Accessed July 21, 2011.

29. Food and Drug Administration. Summary: TranS1 AxiaLIF II System. 2008. Available from: http://www.accessdata.fda.gov/cdrh_docs/pdf7/ K073643.pdf. Accessed July 21, 2011.

30. Aryan HE, Newman CB, Gold JJ, Acosta FL Jr, Coover C, Ames CP. Percutaneous axial lumbar interbody fusion (AxiaLIF) of the L5-S1 segment: Initial clinical and radiographic experience. Minim Invasive Neurosurg. 2008;51:225-230.
31. Stippler M, Turka M, Gerszten PC. Outcomes after percutaneous TranS1 AxiaLIF L5-S1 interbody fusion for intractable lower back pain. Internet J Spine Surg. 2009;5:1-12.

32. Bohinski RJ, Jain VV, Tobler WD. Presacral retroperitoneal approach to axial lumbar interbody fusion: A new, minimally invasive technique at L5-S1: Clinical outcomes, complications, and fusion rates in 50 patients at 1-year follow-up. SAS J. 2010;4:54-62.

33. Akesen B, Wu C, Mehbod AA, Transfeldt EE. Biomechanical evaluation of paracoccygeal transsacral fixation. J Spinal Disord Tech. 2008;21:39-44.

34. Cragg A, Carl A, Casteneda F, Dickman C, Guterman L, Oliveira C. New percutaneous access method for minimally invasive anterior lumbosacral surgery. J Spinal Disord Tech. 2004;17:21-28.

35. Ledet EH, Tymeson MP, Salerno S, Carl AL, Cragg A. Biomechanical evaluation of a novel lumbosacral axial fixation device. J Biomech Eng. 2005;127:929-933.

36. Marotta N, Cosar M, Pimenta L, Khoo LT. A novel minimally invasive presacral approach and instrumentation technique for anterior L5-S1 intervertebral discectomy and fusion: Technical description and case presentations. Neurosurg Focus. 2006;20:E9.

37. Gundanna MI, Miller LE, Block JE. Complications with axial presacral lumbar interbody fusion: a five-year postmarket surveillance experience. $S A S J$. In press.

38. Food and Drug Administration. Summary of safety and effectiveness: BAK interbody fusion system with instrumentation. 1996. Available from: http://www.accessdata.fda.gov/cdrh_docs/pdf/p950002.pdf. Accessed July 21, 2011.

39. Food and Drug Administration. Summary of safety and effectiveness: Ray threaded fusion cage (TFC) with instrumentation. 1996. Available from: http://www.accessdata.fda.gov/cdrh_docs/pdf/P950019a.pdf. Accessed July 21, 2011.

40. Food and Drug Administration. Summary of safety and effectiveness: Inter fix threaded fusion device. 1999. Available from: http://www. accessdata.fda.gov/cdrh_docs/pdf/P970015b.pdf. Accessed July 21, 2011.

41. Food and Drug Administration. Summary of safety and effectiveness: InFUSE bone graft/LT-CAGE lumbar tapered fusion device. 2002 Available from: http://www.accessdata.fda.gov/cdrh_docs/pdf/ P000058b.pdf. Accessed July 21, 2011.

42. Food and Drug Administration. Summary of safety and effectiveness: Prodisc-L total disc replacement. 2006. Available from: http://www. accessdata.fda.gov/cdrh_docs/pdf5/P050010b.pdf. Accessed July 21, 2011.

43. Food and Drug Administration. Summary of safety and effectiveness: Charite artificial disc. 2004. Available from: http://www.accessdata fda.gov/cdrh_docs/pdf4/P040006b.pdf. Accessed July 21, 2011.

44. Nowitzke AM. Assessment of the learning curve for lumbar microendoscopic discectomy. Neurosurgery. 2005;56:755-762.

45. Oto A, Peynircioglu B, Eryilmaz M, Besim A, Surucu HS, Celik HH Determination of the width of the presacral space on magnetic resonance imaging. Clin Anat. 2004;17:14-16.
Medical Devices: Evidence and Research

\section{Publish your work in this journal}

Medical Devices: Evidence and Research is an international, peerreviewed, open access journal that focuses on the evidence, technology, research, and expert opinion supporting the use and application of medical devices in the diagnosis, treatment and management of clinical conditions and physiological processes. The identification of novel

\section{Dovepress}

devices and optimal use of existing devices which will lead to improved clinical outcomes and more effective patient management and safety is a key feature. The manuscript management system is completely online and includes a quick and fair peer-review system. Visit http://www. dovepress.com/testimonials.php to read real quotes from authors. 